\title{
ANN Based Prediction of Performance and Emission Characteristics of a Diesel Engine Fueled by Distilled Tyre Pyrolysis Oil
}

\author{
Obadiah Maube ${ }^{1}$ and Leonard Masu ${ }^{2}$ \\ 1,2Department of Mechanical Engineering Vaal University of Technology, \\ Private Bag X021, Vanderbijlpark, 1900, South Africa.
}

\begin{abstract}
Investigating engine performance and emissions under varying conditions and for different fuels is a costly and timeconsuming exercise. This may also require sophisticated equipment which may not be readily available. In this study, two Analytical Neural Network (ANN) models were developed to predict diesel engine performance and emissions respectively, when fuelled by Distilled Tyre Pyrolysis Oil (DTPO). The models were based on back propagation learning algorithm. The data used to train and test the ANN was experimentally collected from a single cylinder four stroke diesel engine operated at speed ranging from 800 to $3500 \mathrm{rpm}$. The fuel blends contained $0-80 \%$ Distilled Tyre Pyrolysis Oil (DTPO) in diesel fuel. The fuel blends and engine speed were the input variables for each network. The performance of the model was evaluated by comparing experimental and ANN predicted results. The coefficient of determination $\left(\mathrm{R}^{2}\right)$ was found to be $0.9831,0.9977,0.9852,0.9836,0.9961,0.9921$ and 0.997 for Torque, Power, Brake Specific Fuel Consumption, Peak pressure, HC, NOx and $\mathrm{CO}$ respectively. The Mean Square Error between the measured and simulated values was 0.00396 for the engine performance model and 0.000163 for the emissions model. It can be concluded that the engine performance and emissions of a Diesel Engine running on DTPO and its blends with diesel fuel can be reliably predicted using Artificial Neural Network.
\end{abstract}

Key words: tyre pyrolysis oil, diesel engine, emission, performance, Analytical Neural network

\section{INTRODUCTION}

Due to industrialisation and growth in the transport sector, the demand for petroleum products such as diesel fuel has been on the increase. Most countries depend on imported oil and as a result they are vulnerable to fuel price fluctuations which can have a negative impact on their economies. To cope, investment in research for alternative fuels has been on the increase with the aim of getting a fuel that is compatible with the engines and meets the stringent emission norms. Fuels like alcohols and biodiesel have been considered as alternatives to power diesel engines. Conversion of waste to energy is also under investigation. One of these wastes is scrap tyres, which can be taken through the pyrolysis process to produce three products: gas, liquid and char. This liquid is referred to as Tyre
Pyrolysis Oil (TPO) which has similarities with diesel fuel. However, for a fuel to be considered acceptable for use in the diesel engine, apart from fuel properties, several tests have to be performed in a diesel engine under different operating conditions to established its suitability in terms of performance and emissions. Testing the diesel engine under different operating conditions is a time consuming and expensive process that also requires the use of specialised equipment. These equipment may not be readily available. As a result, it may be necessary to develop a predictive model for engine performance.

Engine modelling is carried out for two main purposes, to predict engine performance without performing tests and to determine the parameters that cannot be evaluated experimentally (Richard, 1992). The complexity of the processes in the diesel engine make it difficult to model from first principles, thus engine models rely a lot on experimental data and empirical correlations (Richard, 1992). Estimation of engine performance at given speeds and loads is normally done using engine performance maps, these maps are experimentally generated (Celik \& Arcaklioğlu, 2005, Richard, 1992). The maps mainly display contours of BMEP and BSFC but can also contain plots for emissions, ignition timing and air fuel mixture strength (Richard, 1992). These parameters are plotted graphically against speed. Generating this engine maps is a long and tedious process besides the requirement of skilled personnel and specialised instruments. For example, $400-600$ engine test runs as different combination of speed and load may be required to generate a fuel consumption map for a particular engine (Rawlins, 2005). Due to the lengthy and tedious experimental work involved in the generation of engine maps, machine learning methods such as Artificial Neural Network (ANN) has become an attractive modelling tool.

ANN models are developed from experimental data and have been found suitable in predicting various aspects of the diesel engines performance with acceptable level of accuracy. Ghobadian et al., (2009) found that ANN was satisfactory in predicting Torque, Specific Fuel consumption, $\mathrm{HC}$ and $\mathrm{CO}$ emissions of a diesel engine running on waste cooking oil biodiesel using the backpropagation algorithm. The prediction was done based on blend concentration and engine speed. An analysis performed showed a good relationship between independent experimental data and predicted data with correlation coefficient close to one and a mean square error of 
0.0004. Oğuz et al., (2010) developed an ANN model to estimate the Brake Power, torque, fuel consumption and Specific Fuel Consumption of an engine running on blends of diesel, biodiesel and bioethanol. A statistical t-test analysis between the predicted and experimental results showed no significant difference at $95 \%$ reliability. Nikzadfar \& Shamekhi, (2014) employed an ANN model to investigate the contributive effect of 10 operational parameters on the performance of a common rail diesel engine. A $6 \%$ error was noted between predicted and experimental results. Spray quality as a function of engine variant parameters has been investigated using the Levenburge-Marquardt training Algorithm of ANN by Taghavifar et al., (2014). The spray quality parameters; sauter mean diameter and penetration were predicted with $\mathrm{R}^{2}$ values closer to 1 . Diagnosis of misfiring of one or more cylinders is usually done by measuring cylinder pressure, this requires the installation of a pressure sensor which is a taxing process. Jianmin et al., (2011) use the backpropagation algorithm to diagnose the diesel engine misfire. ANN was able to accurately locate a misfiring cylinder based on cylinder vibration signal. From data of exhaust gas temperature and engine speed, Bietresato et al., (2015) was able to estimate torque and BSFC of a farm tractor engine using ANN. Rawlins, (2005) developed an ANN model to aid in monitoring the performance $f$ the diesel engine operation in industrial set up. Therefore, ANN can be considered a powerful modelling tool to study complex interactions from input output data and make accurate predictions.

In spite of the modelling ability artificial neural network, no investigation to predict engine performance and emissions of a Diesel engine fuelled by DTPO using ANN approach could be found in literature. Therefore, in the present work, experimental data from a previous study was used to train and test ANN models for predicting diesel engine performance (Torque, power, Peak Pressure and BSFC) and emissions ( $\mathrm{HC}, \mathrm{NO}_{\mathrm{x}}$ and $\mathrm{CO})$. The input parameters were engine speed and blend concentration.

\section{METHODOLOGY}

\subsection{Engine performance tests}

The tyre pyrolysis oil used in this work was obtained from local dealers. Blends of diesel and DTPO were prepared containing $0,20,40,60$ and $80 \%$ by mass with diesel were used. The process of preparation and properties can be found in a previous publication (Obadiah et al., 2017). The engine tests were performed on a naturally aspirated, direct injection four stroke, single cylinder TD 302 diesel engine test set with the following characteristics: Continuous rated power of $6.5 \mathrm{~kW}$ at 3600 rev/min; Compression ratio 20.5:1; Engine capacity $462 \mathrm{~cm}^{3}$; Stroke/crank radius $79 \mathrm{~mm} / 38 \mathrm{~mm}$; Connecting rod length 124 $\mathrm{mm}$. The exhaust gaseous emissions were measured using an IMR 2800P gas analyser. The tests were done at speeds of 800 , 1200, 1600, 2000, 2400 2800, 3200 and $3500 \mathrm{rev} / \mathrm{s}$ under SteadyState conditions. At each speed, torque, power fuel consumption, peak pressure and emissions were recorded.

\subsection{Analytical neural topology}

Selection of optimal network topology is the most important thing in ANN modelling, i.e. number of hidden layers, neurons and activation function (Omidvarborna et al., 2016, Roy et al., 2014, Rao et al., 2016). The ANN model in this work was developed on MATLAB 2009a platform, the training parameters are presented on Table 2.2-1. A three-layer network; input, one hidden and output layer was used. The feed forward backpropagation architect was used for modelling.

Table 2.2-1 Training parameters of the proposed ANN model on MATLAB 2009a platform

\begin{tabular}{|l|l|}
\hline Training algorithm & Levenberg-Marquardt algorithm \\
\hline Data partitioning & $\begin{array}{l}\text { Training 70\%; Validation 15\%; } \\
\text { Test Subset 15\% }\end{array}$ \\
\hline $\begin{array}{l}\text { Hidden layer activation } \\
\text { function }\end{array}$ & Logsig \\
\hline $\begin{array}{l}\text { Output layer activation } \\
\text { function }\end{array}$ & Purelin \\
\hline Performance function & Minimum MSE \\
\hline Normalising range & 0 to -1 \\
\hline
\end{tabular}

Two independent models were developed, one for predicting engine performance and the other for predicting engine emissions. Both models had two input variables which are engine speed and blend. For the first model on engine performance, there were four outputs which included power, torque, BSFC and Peak pressure. Therefore, the engine performance network had two input nodes and four output nodes. The emissions model had three output nodes corresponding to $\mathrm{HC}, \mathrm{CO}$ and $\mathrm{NO}_{\mathrm{x}}$. with two input nodes.

Data obtained from experiments was used to train the network. 38 experimental data sets were used for training and testing. $70 \%$ was randomly selected for training, $15 \%$ for testing and $15 \%$ for validation. Other researchers have used this partitioning ratio with satisfactory results (Roy et al., 2014, Omidvarborna et al., 2016). The data was pre-processed and scaled to a range of $0-1$ according to Equation 2.2.1, in compliance with logsig transfer function.

$$
X_{n}=\frac{X_{r}-X_{r, \min }}{X_{r, \max }-X_{r, \min }} *\left(X_{h}-X_{l}\right)+X_{l} \quad \text { Equation 2.2.1 }
$$

Where $X_{n}$ is the normalised variable input, $X_{r}$ raw input variable, $X_{r, \min }$ and $X_{r, \max }$ are maximum and minimum of input variable, and $X_{h}$ and $X_{l}$ are set to 0 and 1 .

The activation functions and training and learning algorithms selected play significant roles in the network modelling. The feed forward back-propagation neural networks with Levenberg-Marquardt training algorithm is popular and has been successfully used to make accurate estimates (Ghobadian et al., 2009, Omidvarborna et al., 2016, Taghavifar et al., 2015, 
Sharma et al., 2016, Rao et al., 2016, Tosun et al., 2016). So Levenberg-Marquardt was chosen as the training algorithm for this study. The purelin transfer function was used in the output layer while the logsig transfer functions were used in the hidden layer. This is a frequently used arrangement of activation functions in ANN modeling and has produced satisfactory results elsewhere (Sharma et al., 2016, Tosun et al., 2016). There is no general criteria for deciding the number of neurons in the hidden layer, it's done by trial and error (Oğuz et al., 2010, Uzun, 2012, Rao et al., 2016). Networks are very sensitive to the number of neurons, too many neurons in the hidden layer can lead to overfitting while too few neurons can lead to under fitting (Hagan, 1995). In this work the number of neurons was adjusted in steps of two from six till the highest correlation coefficient was achieved. The maximum number of epochs was set at 1000 and the correlation coefficient was selected as the function to be maximised.

The training data set was presented to the network and used for training, the gradient is computed and weights and biases are adjusted according to its error. During the training process, the error on the validation set is monitored and training is stopped when generalisation stops improving. The network weights and biases are saved at the minimum of the validation set error. The test data is used to independently check the overall performance of the network. Finally, to evaluate the model prediction ability, a regression analysis of networks output values and the desired target values was performed to investigate the networks generalisation.

\section{RESULTS AND DISCUSSION}

\subsection{Prediction of engine performance using ANN}

An ANN model was created with the aim of predicting Power, torque, sfc and peak pressure based on DTPO blend concentration and engine speed. As mentioned previously, the goal was to maximize the correlation coefficient (R). The optimum number of neurons was found to be 10 with a MSE of 0.00396 for the network. The correlation coefficient for the training, validation and testing data sets was $0.99476,0.99606$ and 0.99699. That for the whole network was 0.99519. The high correlation and low MSE by the model indicate that the model can predict the engine performance adequately.

To analyze the model further, a regression analysis of the predicted Power, torque, sfc and peak pressure, with the measured experimental values was carried out and are shown in Figure 3.1.1 to Figure 3.1.4. From these figures, it is important to note that the predicted values are very close to experimental values, all with $\mathrm{R}^{2}$ higher than 0.98 . The highest accuracy was noted in prediction of power with an $\mathrm{R}^{2}$ value of 0.9977 , then followed by sfc $(0.9852)$ then peak pressure (0.98).

\section{Torque( $\mathrm{Nm})$}

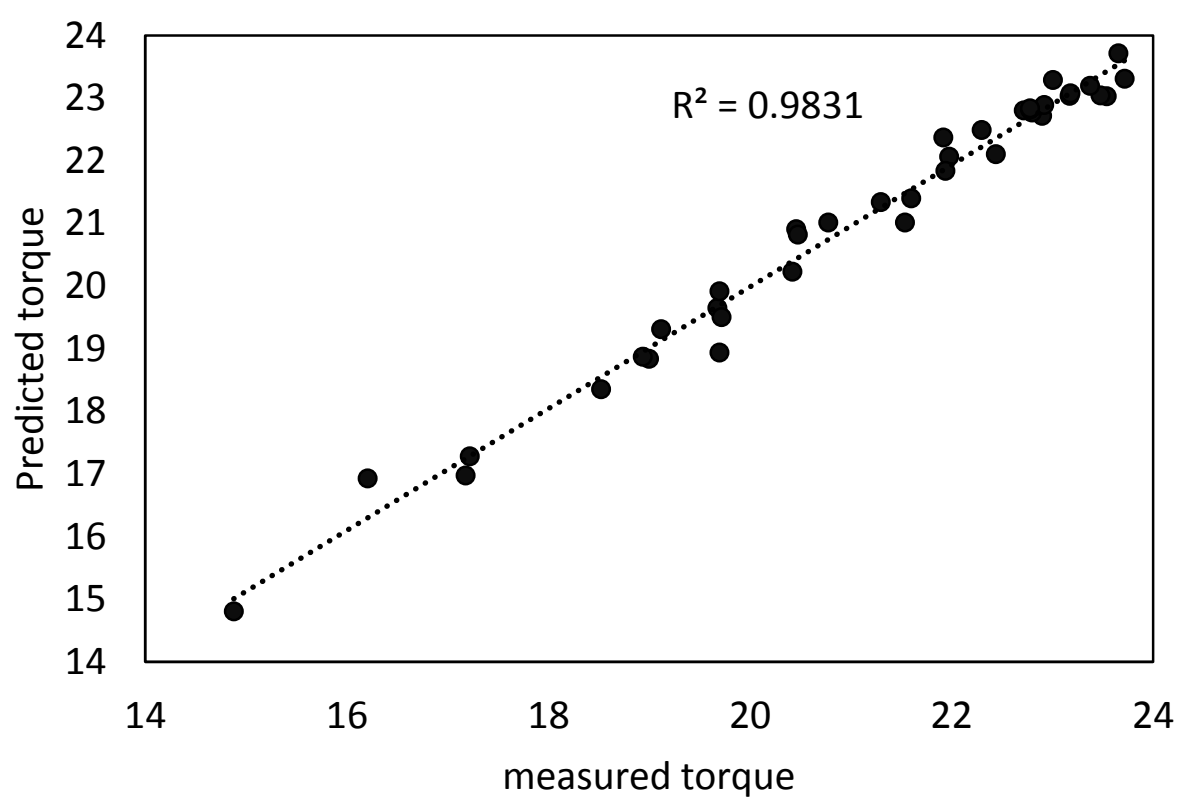

Figure 3.1.1. Predicted and the measured values for engine torque 


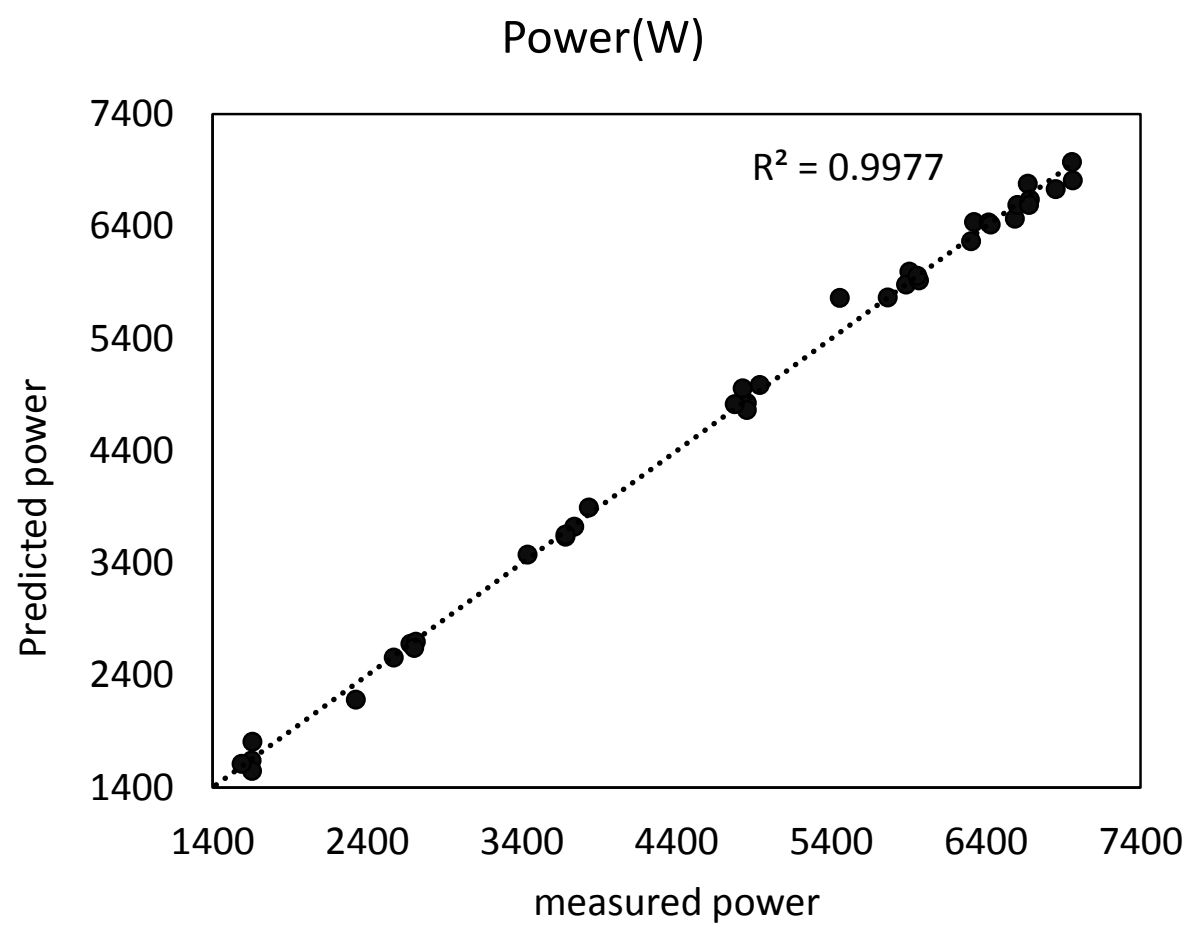

Figure 3.1.2. Predicted and measured values for engine power

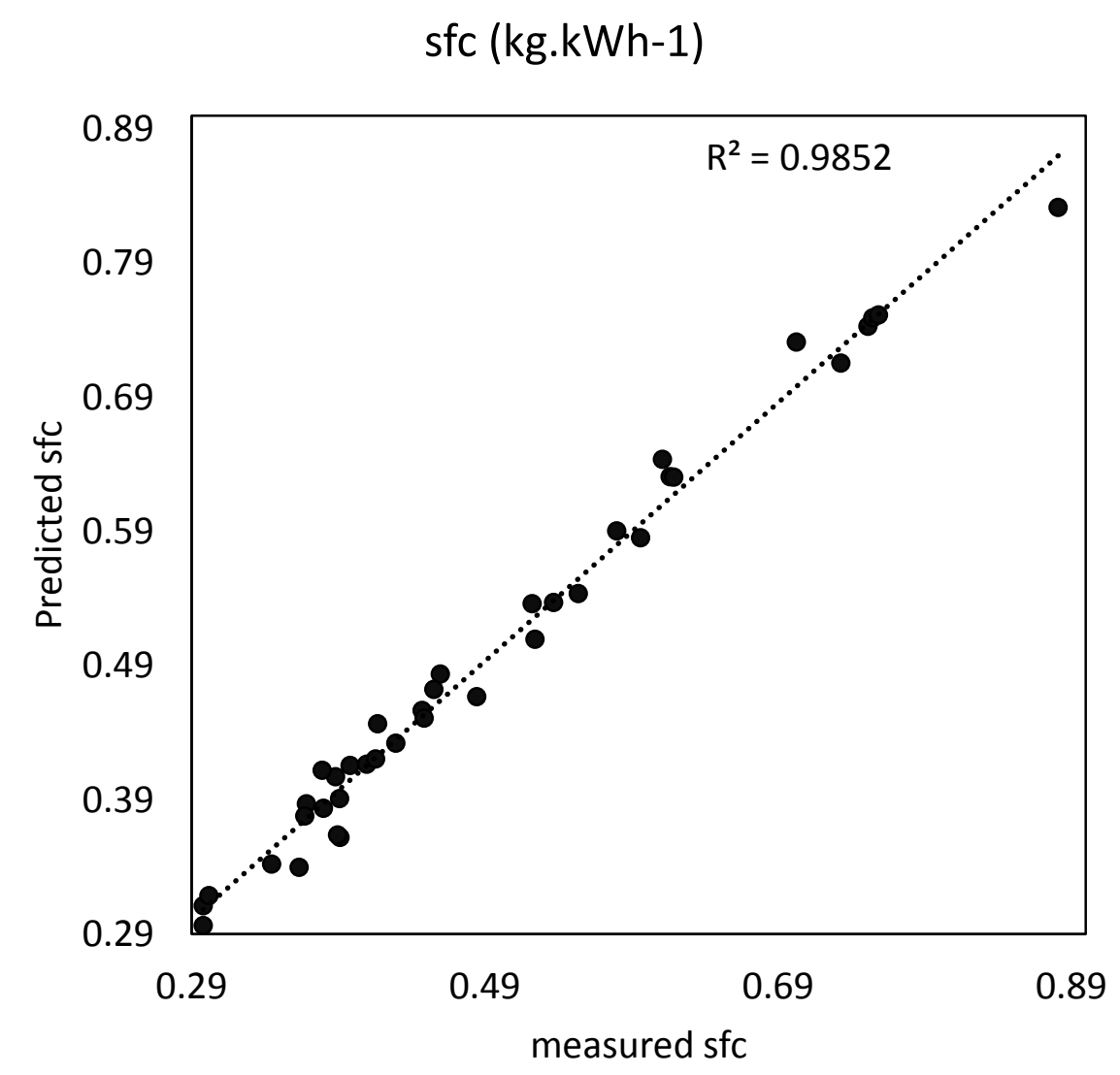

Figure 3.1.3. Predicted vs measured values for SFC 


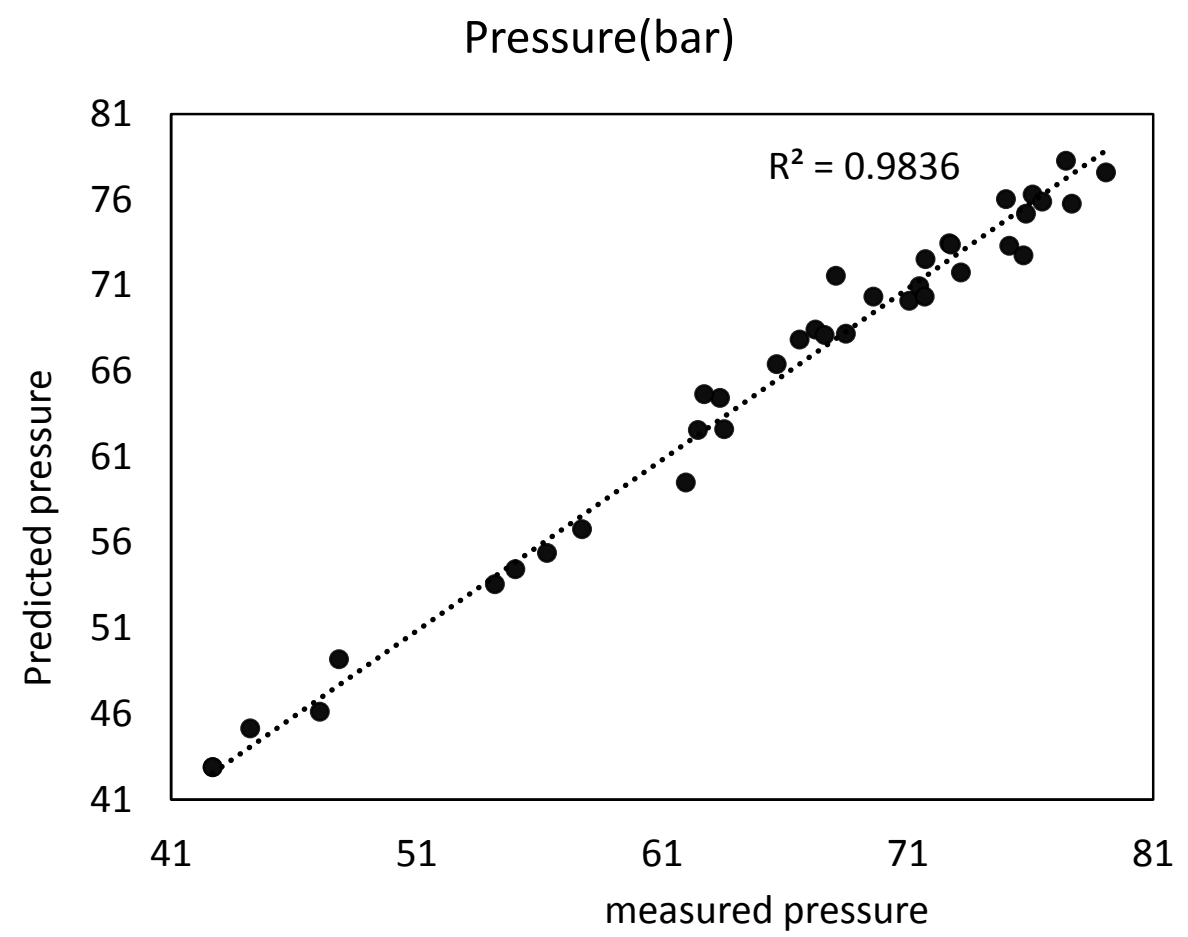

Figure 3.1.4. Predicted and measured values of peak pressure

Additionally, equations for Torque, Power, SFC and Peak pressure were developed and given by Equation 3.1.1 to Equation 3.1.4 . Where $F_{R}$ and $n_{R}$ are defined by equations Equation 3.1.5 and Equation 3.1.6. the weight values are presented in Table 3.1-1.

$$
\begin{gathered}
\text { Torque }=-0.62824 F_{1}-2.27774 F_{2}-4.95962 F_{3}-3.15835 F_{4}+2.396874 F_{5}-0.68893 F_{6}- \\
0.66841 F_{7}+1.148365 F_{8}+0.94004 F_{9}-0.77478 F_{10}+3.11982
\end{gathered}
$$

Power $=-0.39857 F_{-} 1-0.99469 F_{-} 2-1.74611 F_{-} 3-1.15229 F_{-} 4+0.664703 F_{-} 5-0.17873 F_{-} 6-$ $2.29807 F_{-} 7+0.389097 F_{-} 8+0.29911 F_{-} 9-0.39475 F_{-} 10+2.459376$

$$
\begin{gathered}
s f c=0.687379 F_{1}+1.158229 F_{2}+4.013523 F_{3}+2.364102 F_{4}+0.544825 F_{5}+0.128098 F_{6}+ \\
0.39712 F_{7}+0.503372 F_{8} \pm 0.31545 F_{9}+0.410813 F_{10}-4.34864
\end{gathered}
$$

$$
\begin{gathered}
\text { Pressure }=-4.87243 F_{1}-6.89962 F_{2}+0.40131 F_{3}+0.791098 F_{4}+2.109962 F_{5}-0.00679 F_{6}+ \\
0.602341 F_{7}+1.305551 F_{8}+0.71885 F_{9}-0.42125 F_{10}+2.429029
\end{gathered}
$$

$$
F_{R}=\frac{1}{1-e^{-n_{R}}}
$$

$$
n_{R}=(\% D T P O) W_{1 R}+(R P M) W_{2 R}+b_{R}
$$


International Journal of Engineering Research and Technology. ISSN 0974-3154, Volume 13, Number 9 (2020), pp. 2124-2131

(C) International Research Publication House. https://dx.doi.org/10.37624/IJERT/13.9.2020.2124-2131

Table 3.1-1 weights between input and hidden layer for engine performance network

\begin{tabular}{|c|c|c|c|}
\hline $\mathrm{R}$ & $\mathrm{W} 1 \mathrm{R}$ & $\mathrm{W} 2 \mathrm{R}$ & $\mathrm{bR}$ \\
\hline 1 & -9.76025 & -12.4795 & 14.54184 \\
\hline 2 & 6.648437 & 7.144041 & -9.16342 \\
\hline 3 & 1.979585 & -2.15947 & -2.53553 \\
\hline 4 & -3.49731 & 1.656516 & 2.546858 \\
\hline 5 & 2.986831 & -0.98879 & 2.189052 \\
\hline 6 & 6.245957 & 4.506771 & -0.95217 \\
\hline 7 & 0.01654 & -2.35417 & -0.17246 \\
\hline 8 & -9.31786 & 0.50364 & -5.47606 \\
\hline 9 & -0.14736 & 10.10856 & -8.31487 \\
\hline 10 & -5.19179 & -7.23604 & -10.3794 \\
\hline
\end{tabular}

\subsection{Prediction of engine emissions using ANN}

A network with one hidden layer was developed to predict $\mathrm{HC}$, $\mathrm{CO}$ and NOx. A network with 10 neurons was considered satisfactory. The proposed ANN model for predicting $\mathrm{HC}, \mathrm{CO}$ and NOx had correlation coefficients of 0.99761, 0.9991 and 0.99552 for training, test and validation data sets respectively. That for the whole network was 0.9975. Additionally, the MSE was 0.000163 , this shows that the network was able to learn the relationship between the input and output parameters reasonably well.

To further evaluate the prediction ability of the of the ANN, regression curves were plotted for the predicted vs measured $\mathrm{HC}, \mathrm{CO}$ and NOx values as shown in Figure 3.2.1 to Figure 3.2.3. It was found that the $\mathrm{R}^{2}$ values for HC, NOx and CO and were $0.9961,0.9921$ and 0.997 respectively. Based on the high $\mathrm{R}^{2}$ values it can be concluded that the model was able to generalize between the input parameters of engine speed and DTPO blend concentration and the emissions satisfactorily.

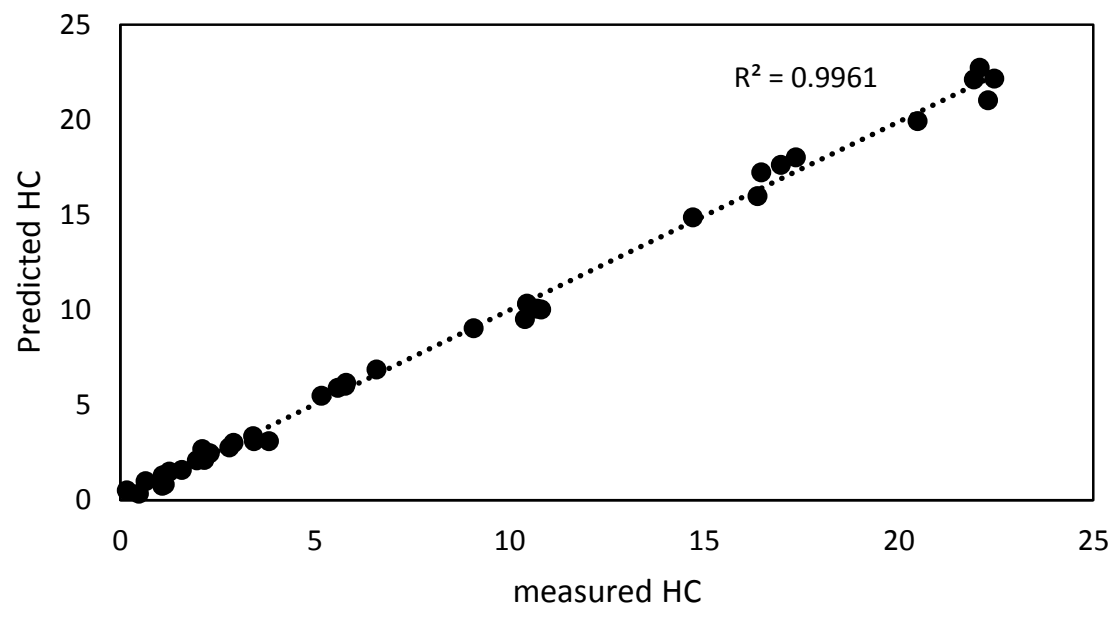

Figure 3.2.1 Predicted and measured values for HC

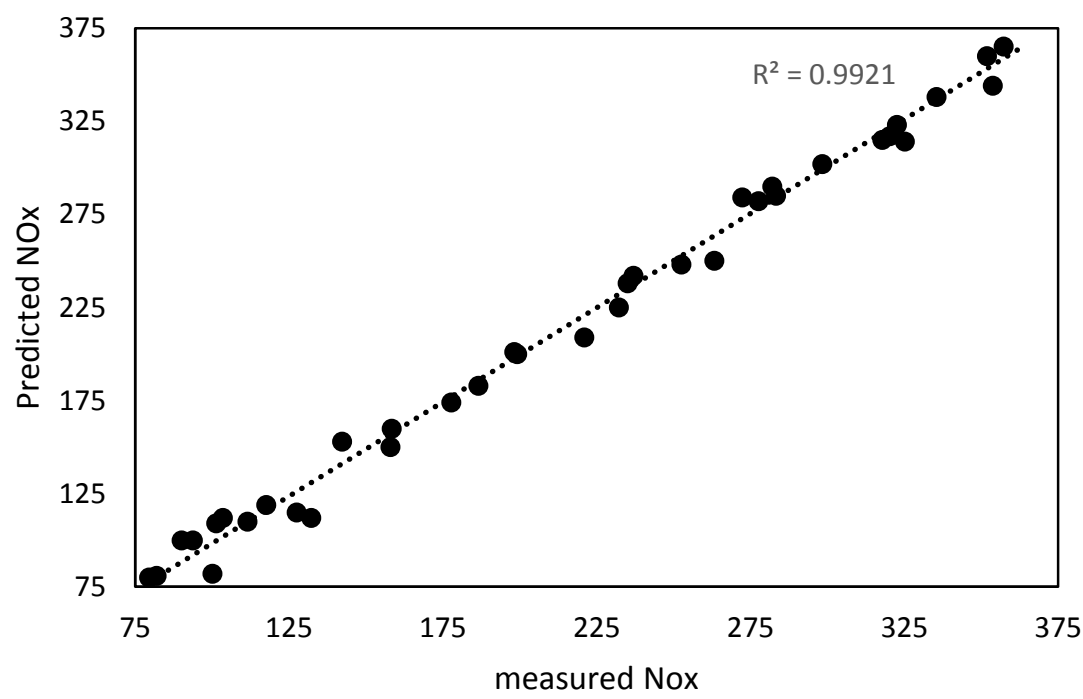

Figure 3.2.2 Predicted and measured values for NOx 
International Journal of Engineering Research and Technology. ISSN 0974-3154, Volume 13, Number 9 (2020), pp. 2124-2131

(C) International Research Publication House. https://dx.doi.org/10.37624/IJERT/13.9.2020.2124-2131

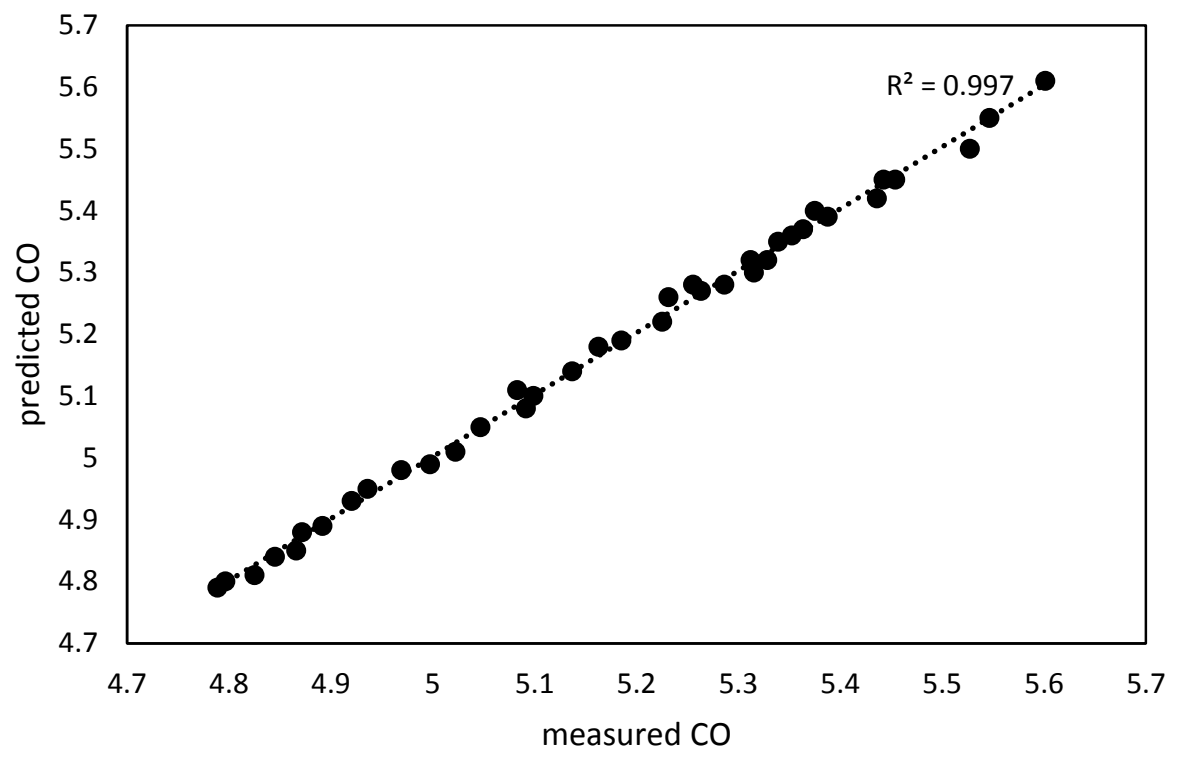

Figure 3.2.3 Predicted and measured values for $\mathrm{CO}$

Using the weights and biases of the trained ANN model presented on Table 3.2-1, Equation 3.2.1 to Equation 3.2.3 were developed for predicting $\mathrm{HC}, \mathrm{CO}$ and NOx respectively. Where $F_{R}$ and $n_{R}$ are defined by equations Equation 3.2.4 and Equation 3.2.5 respectively.
Table 3.2-1 Weights between input and hidden layer for engine performance network

\begin{tabular}{|c|c|c|c|}
\hline $\mathrm{r}$ & $\mathrm{W} 1 \mathrm{r}$ & $\mathrm{W} 2 \mathrm{r}$ & $\mathrm{br}$ \\
\hline 1 & -1.79787 & 7.87059 & 7.152767 \\
\hline 2 & -7.22874 & 2.27573 & 6.371598 \\
\hline 3 & -6.97209 & -5.94619 & 5.622027 \\
\hline 4 & -8.89691 & -1.8935 & 0.869408 \\
\hline 5 & -4.63349 & -6.23566 & -1.68392 \\
\hline 6 & -0.57759 & 4.088858 & 2.202833 \\
\hline 7 & -3.61501 & 3.704252 & -1.93043 \\
\hline 8 & -9.88563 & 1.215642 & -1.97992 \\
\hline 9 & -4.59867 & -5.96368 & -5.77231 \\
\hline 10 & 9.964487 & -4.79473 & 10.47497 \\
\hline
\end{tabular}




\section{CONCLUSION}

Two Models based on ANN were developed and tested, the first one for predicting engine performance and the second for predicting engine emissions when the engine is fuelled by DTPO/Diesel blends. The input parameters were engine speed and blend concentration for both models. The predicted parameters were Power, Brake Specific Fuel Consumption and Peak pressure for the ANN engine performance model while, $\mathrm{HC}, \mathrm{NOx}$ and $\mathrm{CO}$ were predicted parameters for the engine emissions model. Both networks were trained with the use of $70 \%$ of the experimental results, $15 \%$ for validation and the remaining $15 \%$ was used for testing the model. A strong correlation between ANN predicted and expected values was noted with a low MSE for the two models. The first model had a correlation coefficient of 0.99519 with MSE of 0.00396 while the second model had a correlation coefficient of 0.9975 and MSE of 0.000163. Additionally, the coefficient of determination $\left(\mathrm{R}^{2}\right)$ between the predicted and desired values for the seven parameters of both models was above 0.98 . It is therefore concluded that the ANN models can reliably predict four engine performance outputs and three exhaust emission parameters of an engine running on DTPO. Thus, the developed ANN model can be a valuable tool for future research aimed at predicting the engine performance and emission of a diesel engine running on various blends of DTPO and diesel at different speeds. Further research may be carried out in future for predicting other engine parameters such as injection timing and pressure.

\section{REFERENCES}

Bietresato, M., Calcante, A. \& Mazzetto, F. 2015, "A neural network approach for indirectly estimating farm tractors engine performances", Fuel, vol. 143, pp. 144-154.

Celik, V. \& Arcaklioğlu, E. 2005, "Performance maps of a diesel engine", Applied Energy, vol. 81, no. 3, pp. 247259.

Ghobadian, B., Rahimi, H., Nikbakht, A., Najafi, G. \& Yusaf, T. 2009, "Diesel engine performance and exhaust emission analysis using waste cooking biodiesel fuel with an artificial neural network", Renewable Energy, vol. 34, no. 4, pp. 976-982.

Hagan, M.T. 1995, Neural network design, 2nd edn, .

Jianmin, L., Xiaolei, L., Xiaoming, Z., Shiyong, X. \& Lijun, D. 2011, "Misfire diagnosis of diesel engine based on rough set and neural network", Procedia Engineering, vol. 16, pp. 224-229.

Nikzadfar, K. \& Shamekhi, A.H. 2014, "Investigating the relative contribution of operational parameters on performance and emissions of a common-rail diesel engine using neural network", Fuel, vol. 125, pp. 116128.

Obadiah, M., Alfayo, A. \& Leonard, M. 2017, "Characterization and evaluation of distilled tire pyrolysis oil and its potential as a supplement to diesel fuel", Energy Sources, Part A: Recovery, Utilization, and
Environmental Effects, vol. 39, no. 1, pp. 51-57.

Oğuz, H., Sarıtas, I. \& Baydan, H.E. 2010, "Prediction of diesel engine performance using biofuels with artificial neural network", Expert Systems with Applications, vol. 37, no. 9, pp. 6579-6586.

Omidvarborna, H., Kumar, A. \& Kim, D. 2016, "Artificial neural network prediction of NOx emissions from EGR and non-EGR engines running on soybean biodiesel fuel (B5) during cold idle mode", Environmental Progress \& Sustainable Energy, vol. 35, no. 5, pp. 1537-1544.

Rao, K.P., Babu, T.V., Anuradha, G. \& Rao, B.A. 2016, "IDI diesel engine performance and exhaust emission analysis using biodiesel with an artificial neural network (ANN)", Egyptian Journal of Petroleum.

Rawlins, M.S. 2005, Diesel engine performance modelling using neural networks.

Richard, S. 1992, Introduction to Internal Combustion engines, second edn, Macmillan Press LTD.

Roy, S., Banerjee, R. \& Bose, P.K. 2014, "Performance and exhaust emissions prediction of a CRDI assisted single cylinder diesel engine coupled with EGR using artificial neural network", Applied Energy, vol. 119, pp. 330-340.

Sharma, A., Sahoo, P.K., Tripathi, R. \& Meher, L.C. 2016, "Artificial neural network-based prediction of performance and emission characteristics of CI engine using polanga as a biodiesel", International Journal of Ambient Energy, vol. 37, no. 6, pp. 559-570.

Taghavifar, H., Khalilarya, S. \& Jafarmadar, S. 2014, "Diesel engine spray characteristics prediction with hybridized artificial neural network optimized by genetic algorithm", Energy, vol. 71, pp. 656-664.

Taghavifar, H., Taghavifar, H., Mardani, A., Mohebbi, A., Khalilarya, S. \& Jafarmadar, S. 2015, "On the modeling of convective heat transfer coefficient of hydrogen fueled diesel engine as affected by combustion parameters using a coupled numerical-artificial neural network approach", International Journal of Hydrogen Energy, vol. 40, no. 12, pp. 4370-4381.

Tosun, E., Aydin, K. \& Bilgili, M. 2016, "Comparison of linear regression and artificial neural network model of a diesel engine fueled with biodiesel-alcohol mixtures", Alexandria Engineering Journal, vol. 55, no. 4, pp. 30813089.

Uzun, A. 2012, "A parametric study for specific fuel consumption of an intercooled diesel engine using a neural network", Fuel, vol. 93, pp. 189-199. 